ARTIGO

\title{
Políticas educacionais e o financiamento dos centros concertados na Espanha*
}

\author{
Jani Alves da Silva Moreira a \\ Ângelo Ricardo de Souza ${ }^{b}$ \\ José María Hernández Díaz c
}

\section{Resumo}

O artigo é resultado de uma pesquisa exploratória e documental, que teve como objetos as políticas educacionais, a gestão e o financiamento dos Centros Concertados de Educação Infantil e Educação Primária na Espanha. Investigam-se os aspectos históricos e políticos quanto à estrutura e à organização da política educativa, a partir do processo de descentralização, naquele país, bem como o papel do Conselho Escolar na formulação da política educacional espanhola. Ademais, o artigo busca compreender os aspectos relacionados com a manutenção do ensino nos Centros Concertados de Educação Infantil e de Educação Primária, a fim de apreender os pressupostos orçamentários. O resultado evidenciou a necessidade de manutenção da participação coletiva para a construção de políticas educacionais mais equitativas e não segregatórias na Espanha.

Palavras-chave: Políticas Educacionais. Financiamento da Educação. Centros Concertados. Educação Infantil. Educação Primária. Espanha.

\section{Introdução}

O texto é resultado de uma investigação sobre as políticas educacionais, na Espanha, no que se refere à gestão e ao financiamento dos Centros Concertados de Ensino, em especial, para a Educação Infantil e a Educação Primária, com

\footnotetext{
* O presente texto é resultado da pesquisa de Pós-Doutorado realizada no Programa de Pós-Graduação em Educação da Universidade Federal do Paraná, com estágio Pós-Doutoral na Universidad de Salamanca- España, financiada pela Fundação Araucária de Apoio e Desenvolvimento Científico e Tecnológico - Convênio nº 35/2019.

a Universidade Estadual de Maringá, Maringá, PR, Brasil

b Universidade Federal do Paraná, Curitiba, PR, Brasil

c Universidad de Salamanca, Salamanca, España
} 
base no recorte temporal de 2016-2017 . A temática abordada tangencia questões inerentes à gestão e ao financiamento da Educação não universitária ${ }^{2}$, e também, a relação entre setor público e o setor privado, na Espanha. Quanto à especificidade, a análise priorizou o financiamento público concedido às escolas que são contratadas pelos estados e são gestadas pelo setor privado, a fim de compreender os aspectos relacionados com a gestão e o financiamento educacional.

A problemática da investigação diz respeito a um aspecto específico da arquitetura do financiamento da Educação, isto é, a relação entre setor público e setor privado, no que concerne ao financiamento público dos Centros Concertados para a Educação Infantil e a Educação Primária na Espanha. Trata-se de uma pesquisa exploratória, de análise documental e bibliográfica, por meio dos dados presentes nos documentos oficiais do Ministério da Educação e Formação Profissional e do Conselho Escolar ${ }^{3}$ da Espanha. Procurou-se compreender a política educacional presente nos documentos, os quais "expressam determinações históricas que estão no cerne da documentação pesquisada" (EVANGELISTA; SHIROMA, 2019, p. 98). Considera-se que a política educacional se refere ao processo em que o Estado exerce o seu poder e o seu controle, no campo da ordenação, planejamento e legislação educacional. Todavia, pode haver ou não o consentimento de outras frentes, atuações e representatividades da sociedade (MOREIRA, 2015); assim, esse processo traduz-se na luta por poder, de maneira que o objetivo de "[...] conquistá-lo, mantê-lo e ampliá-lo, compõe o contexto dos conflitos que ganham espaço na relação entre as demandas sociais por Educação e o posicionamento do Estado diante destas demandas, seja atendendo-as ou não" (SOUZA, 2015, p. 76).

Como questões centrais, ao longo do texto, almeja-se discorrer sobre: Como se configuram as políticas de financiamento público para os Centros Concertados de Educação Infantil e Educação Primária na Espanha? Qual a atuação do Conselho Escolar

\footnotetext{
O recorte temporal justifica-se, em virtude do fato de os dados coletados no período da investigação serem de 2016-2017.

2 O termo "educação não universitária" designa as etapas referentes a: Educação Infantil (primeiro ciclo - 0 a 3 anos e segundo ciclo - de 3 a 6 anos, Educação Primária (6 a 12 anos), ensinos elementares de música e dança na Educação Primária, Educação Secundária (ESO): primeiro ciclo - 12 a 15 anos, segundo ciclo - 15 e 16 anos, com a formação profissional básica e o bacharelado (ensino pós-obrigatório de caráter pré-universitário), ensino de idiomas, formação de pessoas adultas (ESPAÑA, 2018a; EURYDICE, 2019). Na Espanha, a Educação Básica refere-se às etapas da Educação Primária e da Secundária obrigatórias, com 10 anos de duração, e contempla a faixa etária dos 6 aos 16 anos (SOUZA; BATISTA, 2018).

3 O Conselho Estadual de Ensino é um órgão de participação dos representantes dos segmentos educacionais. Os membros do Conselho propõem projetos de lei em matéria educacional, os quais são aprovados pela Assembleia da República, pelo Governo ou pelo chefe do Ministério da Educação. Em cada ano letivo, é o Conselho que aprova o Relatório sobre a situação do sistema educacional, que inclui as propostas de melhoria da Educação no país. Por outro lado, o Conselho Estadual de Escola integra a participação territorial dos diferentes Conselhos Escolares Autônomos, por meio do Conselho de Participação, composto pelos respectivos presidentes e presidido pelo presidente do Conselho Estadual de Escola (ESPAÑA, 2020).
} 
quanto ao planejamento, à organização e ao monitoramento das políticas nacionais para os Centros Concertados? Ao responder tais inquietações, dispõe-se sobre os aspectos gerais da política e da gestão da Educação, que perpassam a relação entre os setores público e privado, bem como o seu financiamento por meio do fundo público.

Além dessa introdução, o presente texto organiza-se em mais três seções. A seção dois discorre sobre a relação entre as políticas para o financiamento público dispensado aos Centros Concertados e acerca do papel do Conselho Escolar na Espanha. A seção três examina os principais aspectos relacionados com a manutenção dos Centros Concertados de Educação Infantil e de Educação Primária na Espanha. Por fim, na última seção, são apresentadas as considerações finais a respeito do tema aqui discutido, a partir de algumas inquietações e conjecturas.

\section{Políticas de financiamento público para os Centros Concertados e o papel do Conselho Escolar do Estado}

O Financiamento da Educação tem sido tema de investigação crescente na Europa, sobretudo, a partir da crise econômica de 2008 e devido à pressão para que os gastos públicos no setor público resultem em maior eficiência (EURYDICE, 2014).

As políticas de financiamento provenientes do processo de descentralização política na Espanha, como os mecanismos de implantação dos Centros Concertados, foram consideradas como meios de modernização da Educação. Hernández-Díaz, ao apresentar notas sobre a modernização educativa na história ibero-americana, enfatiza que existe uma visível heterogeneidade procedente do passado, que pode ser considerada como desencadeante do modo como a política educativa se delineia na atualidade. Dentre esses aspectos, destacam-se a presença marcante das ordens religiosas, a necessidade de superação do modelo tradicional de ensino e a presença marcante das teses da teoria do capital humano que, em alguns casos, apoiavam-se em estruturas políticas militares.

O conturbado processo de implementação da política de descentralização $0^{4}$ da Educação, no país, somente teve a sua legalidade prescrita, em especial, no que se refere à relação entre Estado e Educação, a partir do estabelecido no Art. 27 da Constituição Espanhola (CE), de 1978 (ESPAÑA, 1978), e nos Artigos 138.1, 149.1,

\footnotetext{
A descentralização da Educação consiste em um conceito polissêmico e, por esse motivo, esclarece-se que a política de descentralização mencionada no texto refere-se ao período do fim da ditadura franquista, no qual, por meio da consolidação do Estado democrático, e com a liberdade e o pluralismo político, as CCAA tiveram participação democrática para definirem os fins da Educação Pública, como também, o Conselho Escolar. Portanto, na Espanha, a descentralização da Educação foi parte da democratização, no qual o Estado espanhol tornou-se, ao mesmo tempo, descentralizado e democrático (PUELLES-BENÍTEZ, 1996).
} 
158.1 e 158.2 quanto à solidariedade e seus desdobramentos na Educação do Estado Autônomo 5 . A Constituição Espanhola (CE), composta por 169 artigos, sancionou o Estado Social e Democrático de Direito na Espanha e estabeleceu os pilares para a organização de uma sociedade democrática pautada na liberdade, na justiça e no pluralismo político (Artigo 1.1.). Estabeleceu-se o marco legal para a consolidação das políticas de descentralização com a aprovação dos Estatutos Autônomos, que são autênticas leis do Estado de caráter orgânico. Conforme o artigo 147.1, a Constituição Espanhola estabelece que: "1. Dentro dos termos da presente Constituição, os Estatutos serão a norma institucional básica de cada Comunidade Autónoma que o Estado reconhecerá e amparará como parte integrante de seu ordenamento jurídico".

Em especial no parágrafo $5^{\circ}$, do artigo 27 da CE (ESPAÑA, 1978), ao se referir à participação efetiva de todos os setores afetos à Educação na planificação geral do ensino no país, são instituídos os pilares da atuação do setor privado junto ao setor público, o que se efetiva mediante participação e consulta dos Conselhos Escolares e demais representações. No Título IV da Lei Orgânica ${ }^{6}{ }^{0}$ 8/1985 (ESPAÑA, 1985), que regulamenta o Direito à Educação (LODE), foram instituídas as grandes linhas do modelo atual do regime de concertos da Educação não universitária.

A criação do Conselho Escolar da Espanha tem suas origens no ano de 1834, com o Conselho de Instrução Pública, enquanto órgão consultivo. Foi em pleno contexto de (in) civil guerra, considerada a maior catástrofe histórica da Espanha, que teve início a longa ditadura nazista (1936-1939) e franquista (1936-1975). A partir da Lei de 13 de agosto de 1940 (ESPAÑA, 1940), criou-se o Conselho Nacional de Educação, mas com um caráter técnico e funcionalista, marcado pela centralização, que ainda havia naquele período, que antecedeu a democratização, em que o próprio Ministro da Educação era quem presidia o Conselho. Todavia, foi com a Lei da Educação no 14 de 1970 (ESPAÑA, 1970) que se introduziu a atribuição do relatório obrigatório das contas pelo Conselho, uma atividade importante que permanece até os dias atuais.

\footnotetext{
Composto por Comunidades Autónomas (CCAA) são territórios que formam parte da Organização do Estado e que, de acordo com a Constituição Espanhola (ESPAÑA, 1978), gozam de autonomia e gestão de seus respectivos interesses. Existem 17 Comunidades Autônomas: Andalucía, Aragón, Asturias, Baleares, Cantabria, Comunidade Valenciana, Extremadura, Galicia, Comunidade de Madrid, Região de Murcia, Comunidade Foral de Navarra, País Vasco, Rioja (ESPAÑA, 2016).

6 A Espanha teve oito Leis Orgânicas para a Educação aprovadas, sendo elas: Lei Orgânica Reguladora do Estatuto de Centros Escolares, LOECE, 1980 (UCD); Lei Orgânica do Direito à Educação, LODE, 1985 (PSOE); Lei Orgânica de Ordenação Geral do Sistema Educativo, LOGSE, 1990 (PSOE); Lei Orgânica 9/1995 (LOPEG); Lei Orgânica de Qualidade da Educação, LOCE, 2002 (PP); Lei Orgânica 5/2002 (Das Qualificações e da Formação Profissional); Lei Orgânica de Educação, LOE, 2006 (PSOE); Lei Orgânica para a Melhoria da Qualidade Educativa, LOMCE, 2013 (PP). Disponível em; http://todofp.es/profesores/biblioteca-todofp/ normativa-de-educacion/leyes-organicas-de-educacion.html. Acesso em: 1 maio 2020.
} 
Contudo, foi com a Lode (ESPAÑA, 1985) que se estabeleceu a organização e a estruturação do Conselho Escolar do Estado, enquanto órgão do Ministério da Educação e Formação Profissional (MEFP) ${ }^{7}$ da Espanha; atualmente, o órgão possui imprescindível representatividade em cada Junta das Comunidades Autônomas (CCAA), por meio dos seus Conselhos Locais. A Lode qualificou o Conselho Escolar do Estado como um órgão participativo de todos os setores para a programação geral e o assessoramento do ensino (Art. 30). Visou-se essencialmente à participação democrática no planejamento ${ }^{8}$ da Educação espanhola, incorporando, pela primeira vez, as representações dos estudantes, da administração e do pessoal de serviços, além das centrais sindicais e organizações de empregadores do órgão colegiado representativo, com regras de equilíbrio na composição, conforme o estabelecidopelo Real Decreto $n^{\circ}$ 694/2007 (ESPAÑA, 2007).

Perante a Administração Estadual, do Ministério da Educação e de diversos atores influentes no campo da política educacional, o Conselho Escolar é reconhecido por sua representação democrática, enquanto fórum de debate político; ao relatar projetos de lei importantes, o Conselho caracterizou-se como um órgão de câmara parlamentar, pois, em certas ocasiões, impede a obtenção de um consenso básico na Educação. Outro aspecto importante é o fato de que a legislação atual estabelece que o Conselho Escolar Estadual apresente propostas referentes a assuntos como programação geral de Educação, igualdade de direitos e de oportunidades na Educação, organização geral do sistema educacional. E ainda pode apresentar propostas relacionadas com a qualidade do ensino, bem como planejar adequadamente os requisitos do princípio da participação nacional dos setores afetos com os que derivam do princípio da participação territorial nas suas Comunidades (PUELLES-BENITEZ, 2005).

Carnoy (1999) salienta que as políticas de descentralização causaram efeitos em três direções principais. A primeira delas foi a redução do gasto público com a Educação, o que desencadeou um enfraquecimento geral da Educação Pública, mediante diversas variações ideológicas de diferentes governos, uma polarização de distintas fontes de financiamento, privatização e participação das famílias com

\footnotetext{
Em 6 de junho de 2018, pelo Real Decreto 355/2018, o nome do Ministério de Educação e Esporte foi extinto e passou a ser denominado como Ministério de Educação e Formação Profissional. É importante salientar que, ao longo da história da Espanha, esse Ministério já teve diversos nomes.

8 Sobre a temática Gestão da Educação, no que se refere ao Planejamento e planos de Educação na Espanha, recomendamos os resultados evidenciados por Souza (2021), em sua investigação, na qual revelou aspectos que interferem na produção acadêmica e científica sobre essa temática, sendo eles: "a) dos processos de regulação supranacionais, traduzidos pelo crescente declínio do interesse por estudos relativos ao planejamento da Educação e, a um só tempo, ascensão dos trabalhos que se restringem ao exame de objetivos, metas e estratégias consolidadas em planos de Educação; b) da fragmentação do planejamento da Educação em uma série de planos pontuais, quase sempre desvinculados entre si; e, ainda, c) de processos pouco participativos de planejamento e elaboração desses planos, no âmbito do governo central, portanto, à margem de sua discussão e elaboração sociopolítica" (SOUZA, 2021, p. 12).
} 
os gastos na Educação dos filhos. A segunda direção refere-se à própria formação escolar, que recebeu contornos das exigências para a mão de obra qualificada, sobretudo na formação secundária e superior, enquanto que para a Educação Básica predominou a formação geral. $\mathrm{O}$ terceiro efeito refere-se às mudanças curriculares, cuja ênfase concentrou-se nas Ciências e na Matemática, de maneira que prejudicou as demais áreas do conhecimento e, assim, incorporou o caráter economicista na Educação, tanto na vertente privada - do desenvolvimento integral e da personalidade do indivíduo - quanto na vertente pública - nos fatores culturais, sociais e políticos da Educação em uma sociedade democrática.

No que concerne aos Centros Concertados de Educação Infantil e Educação Primária, em especial suas políticas de financiamento, foram selecionados para a análise dois documentos recentes do Conselho Escolar do Estado que apresentam dados do biênio 2016-2017, sendo eles: a) o Informe 2018 sobre el estado del sistema educativo: curso 2016-2017 (ESPAÑA, 2018b); b) Indicadores comentados sobre el estado del sistema educativo español 2018(FUNDACIÓN EUROPEASOCIEDADYEDUCACIÓN,2018).

O Informe 2018 sobre el estado del sistema educativo: curso 2016-2017 (ESPAÑA, 2018b) apresenta aspectos importantes sobre o conjunto de ações administrativas, dados sobre os profissionais da Educação e agentes públicos e privados que atuam no desenvolvimento das funções de regulação, financiamento e prestação de serviços para a garantia do direito à Educação no país, como também, medidas e ações. O documento ainda apresenta as propostas e recomendações dos membros do Conselho Escolar do Estado (CEE) que norteiam a melhoria do sistema educativo espanhol. Em sua essência, o documento constitui-se como base e fundamento para as decisões futuras no campo da política educativa espanhola.

Vale ressaltar duas categorias políticas prioritárias com relação ao financiamento da Educação e às políticas para a sua definição: a obrigatoriedade e a gratuidade. A Constituição Espanhola estabelece, no Art. 27, como já mencionado, que a Educação Básica é gratuita. Na atual Lei Orgânica (LOE) n 2 de 2006 (ESPAÑA, 2006), de 3 de maio, no Art. 3, parágrafo 3, consideram-se, como níveis obrigatórios e gratuitos, o Ensino Primário e o Ensino Secundário, no âmbito da Educação Básica. A Educação Infantil não é considerada uma etapa obrigatória no país. No art. 15, seção 2 da LOE, encontra-se firmado que o segundo ciclo da Educação Infantil também é gratuito, mas não obrigatório, pois tem o caráter voluntário (Art. 12.2). No art. 3.10 está estabelecido que os ciclos básicos de Formação Profissional são de oferta obrigatória e gratuita.

Outra questão firmada pela $\mathrm{LOE}^{\circ} 2$ de 2006 (ESPAÑA, 2006), mas proveniente da Lei Orgânica no 8 de 1985, no Título IV, que regulamenta o Direito à Educação, 
são os mecanismos de conveniamento e de concertação, que deram origem aos Centros Concertados - instituições financiadas com fundo público; assim, estabeleceu-se na LOE (ESPAÑA, 2006) que o sistema privado de concertação exerceria um caráter complementar no sistema público, com a obrigatoriedade de transmitir gratuitamente as aulas e as ações pedagógicas sem fins lucrativos.

A administração pública se compromete a financiar os custos dos professores e as despesas para o funcionamento dos Centros Concertados, de modo que o financiamento é estabelecido no Orçamento Geral do Estado. Há atividades extracurriculares que também são ofertadas pelos Centros Concertados, contudo, como regime opcional, de forma que poderão cobrar taxas complementares para a sua realização. Quanto à admissão de alunos nos Centros Concertados e nos Centros Públicos, os critérios devem ser os mesmos. Nos orçamentos gerais do Estado são estabelecidos os recursos a serem destinados para o custeio do pessoal docente e para as despesas de funcionamento dos Centros Concertados (TORRUBÍA; EMBÚN, 2009).

\section{Manutenção do Ensino nos Centros Concertados de Educação Infantil e Educação Primária}

Ao abordar os principais aspectos relacionados com a manutenção dos Centros Concertados de Educação Infantil e Educação Primária na Espanha, elegeu-se como foco a origem dos recursos públicos provenientes do orçamento do Estado, como eles se constituem e de que forma são repassados e distribuídos para a manutenção dos Centros Concertados no país.

Tendo em vista que o primeiro ciclo da Educação Infantil não é totalmente gratuito, desde a LOE (ESPAÑA, 2006), a Espanha tem promovido espaços educativos financiados, de forma progressiva com fundo público, em parceria com as administrações educativas autônomas. São essas administrações que ostentam a titularidade do Centro e, na sua maioria, os municípios estabelecem as cotas que as famílias devem pagar nos Centros Públicos Concertados. Mediante o informe da OCDE (ESPAÑA, 2016), as administrações educativas definem os preços públicos máximos dos centros, levando-se em conta os rendimentos da unidade familiar, a extensão do horário de permanência no Centro, a utilização do serviço de alimentação e outros aspectos, como a assistência do Centro para mais de um filho.

A fase da Educação Primária é gratuita nos Centros sustentados com fundos públicos, uma vez que a LOE (ESPAÑA, 2006) ampliou a gratuidade, a partir do segundo ciclo da Educação Infantil ( 3 a 6 anos). Portanto, nessas etapas, as famílias custeiam apenas o material escolar, livros de textos e os serviços complementares 
da alimentação e do transporte escolar. Ressalta-se que existem as ajudas (becas) que auxiliam a cobrir esses gastos. As atividades extraclasses são voluntárias e os custos também são mantidos pelos participantes (ESPAÑA, 2016).

As taxas correspondentes ao Seguro Escolar na matrícula do aluno, nas etapas da Educação Infantil, Educação Primária e também na Educação Secundária Obrigatória (ESO) proporcionam a assistência sanitária do Seguro Social, em todo o território nacional, cujas legislação e competência são do Estado e se encontram estabelecidas no Art. 149. 1-17 da Constituição Espanhola (ESPAÑA, 1978).

Dados atuais do Anuário Estatístico da Espanha, publicado em 2018, expostos na Tabela 1, evidenciam que nas 17 Comunidades Autônomas e nas duas Cidades Autônomas $^{9}$ - Ceuta e Melilla - têm-se um maior quantitativo de unidades escolares de Centros Concertados de Ensino, em comparação com o quantitativo de Centros Privados Não Concertados.

Tabela 1 - Unidades escolares e alunado matriculado na Educação Infantil por Comunidade Autônoma (2015-2016)

\begin{tabular}{|c|c|c|c|c|c|c|c|}
\hline & \multicolumn{2}{|c|}{$\begin{array}{l}\text { Unidades } \\
\text { escolares }^{1}\end{array}$} & \multirow{2}{*}{\multicolumn{2}{|c|}{ Centros privados }} & \multicolumn{3}{|c|}{ Alunos matriculados } \\
\hline & \multirow[b]{2}{*}{ Total } & \multirow{2}{*}{$\begin{array}{l}\text { Centros } \\
\text { públicos }\end{array}$} & & & Total & Pública & Privada \\
\hline & & & Concertados $^{2}$ & $\begin{array}{c}\text { Não } \\
\text { concertados }\end{array}$ & Total & Total & Total \\
\hline Total & 99.089 & 62.722 & 21.522 & 14.845 & 1.808 .322 & 1.150 .996 & 657.326 \\
\hline Andalucia & 19.516 & 12.664 & 5.377 & 1.475 & 359.201 & 242.029 & 117.172 \\
\hline Aragón & 2.793 & 1.806 & 460 & 527 & 48.296 & 31.240 & 17.056 \\
\hline $\begin{array}{l}\text { Asturias, } \\
\text { Principado de }\end{array}$ & 1.503 & 1.141 & 280 & 82 & 26.846 & 19.279 & 7.567 \\
\hline Balears, Illes & 2.293 & 1.442 & 463 & 388 & 38.153 & 24.240 & 13.813 \\
\hline Canarias & 3.149 & 2.070 & 492 & 587 & 59.104 & 40.244 & 18.860 \\
\hline Cantabria & 1.052 & 755 & 235 & 62 & 19.291 & 13.845 & 5.446 \\
\hline Castilla y León & 3.877 & 2.715 & 839 & 323 & 69.203 & 45.846 & 23.357 \\
\hline $\begin{array}{l}\text { Castilla-La } \\
\text { Mancha }\end{array}$ & 4.570 & 3541 & 514 & 515 & 79.545 & 60.940 & 18.605 \\
\hline Cataluõa & 16.425 & 10.827 & 3.016 & 2.582 & 310.195 & 204.514 & 105.681 \\
\hline
\end{tabular}

\footnotetext{
9 Cidades Autônomas são as duas cidades, Ceuta e Melilla, que formam parte do território de soberania espanhola e não têm status de Comunidade Autônoma. Sua Educação depende, exclusivamente, do Ministério da Educação e Formação Profissional (ESPAÑA, 2016).
} 
Continuação

\begin{tabular}{|c|c|c|c|c|c|c|c|}
\hline & \multicolumn{2}{|c|}{$\begin{array}{l}\text { Unidades } \\
\text { escolares }^{1}\end{array}$} & \multirow{2}{*}{\multicolumn{2}{|c|}{ Centros privados }} & \multicolumn{3}{|c|}{ Alunos matriculados } \\
\hline & \multirow[b]{2}{*}{ Total } & \multirow[b]{2}{*}{$\begin{array}{l}\text { Centros } \\
\text { públicos }\end{array}$} & & & Total & Pública & Privada \\
\hline & & & Concertados $^{2}$ & $\begin{array}{c}\text { Não } \\
\text { concertados }\end{array}$ & Total & Total & Total \\
\hline $\begin{array}{l}\text { Comunitat } \\
\text { Valenciana }\end{array}$ & 9.844 & 5.900 & 1.720 & 2.224 & 183.491 & 111.072 & 72.419 \\
\hline Extremadura & 2.295 & 1.943 & 276 & 76 & 37.545 & 30.208 & 7.337 \\
\hline Galicia & 5.260 & 3.523 & 1.062 & 675 & 88.821 & 58.805 & 30.016 \\
\hline $\begin{array}{l}\text { Madrid, } \\
\text { Comunidad de }\end{array}$ & 15.598 & 7.606 & 3302 & 4.690 & 290.128 & 149.869 & 140.259 \\
\hline $\begin{array}{l}\text { Murcia, } \\
\text { Región de }\end{array}$ & 2.965 & 1.982 & 612 & 371 & 59.332 & 39.100 & 20.232 \\
\hline $\begin{array}{l}\text { Navarra }^{3} \text {, } \\
\text { Comunidad } \\
\text { Foral dei }\end{array}$ & 1.413 & 1.040 & 297 & 76 & 24.628 & 16.424 & 8.204 \\
\hline País Vasco & 5.488 & 3.077 & 2.381 & 30 & 93.318 & 48.921 & 44.397 \\
\hline Rioja, La & 689 & 424 & 135 & 130 & 12.294 & 7.627 & 4.667 \\
\hline Ceuta & 166 & 126 & 30 & 10 & 4.100 & 3.102 & 998 \\
\hline Melilla & 193 & 140 & 31 & 22 & 4.831 & 3.591 & 1.240 \\
\hline
\end{tabular}

Fonte: Anuario Estadístico de España (INE, 2018, p. 72)

${ }^{1} \mathrm{No}$ "primeiro ciclo" apenas as unidades estão incluídas nos centros autorizados pela Administração Educacional.

${ }^{2}$ Todas as unidades/grupos em operação de centros privados com qualquer unidade/grupo combinados nesse Ensino/nível são consideradas.

${ }^{3} \mathrm{Na}$ Comunidade Autônoma de Navarra existem também 10 entros públicos de Educação Infantil de primeiro ciclo, com 778 alunos no processo de verificação de requisitos pelo Departamento de Educação.

Como se pode ver, ainda prevalece um maior quantitativo de Centros Públicos de Ensino na Educação Infantil nas CCAA. Na Tabela 1, visualiza-se a disposição do quantitativo das unidades escolares para a Educação Infantil. Observa-se a prevalência de um quantitativo maior para os Centros Públicos, com exceção da região de Murcia. A relação desse maior quantitativo de Centros Públicos de Educação Infantil também é diretamente proporcional ao quantitativo de aluno matriculado.

No que se refere ao quantitativo de Centros de Educação Primária e de Unidades escolares mistas, de Educação Infantil e de Educação Primária, os dados também demonstram que ainda permanece um maior quantitativo de Centros Públicos, conforme disposto na Tabela 2. 


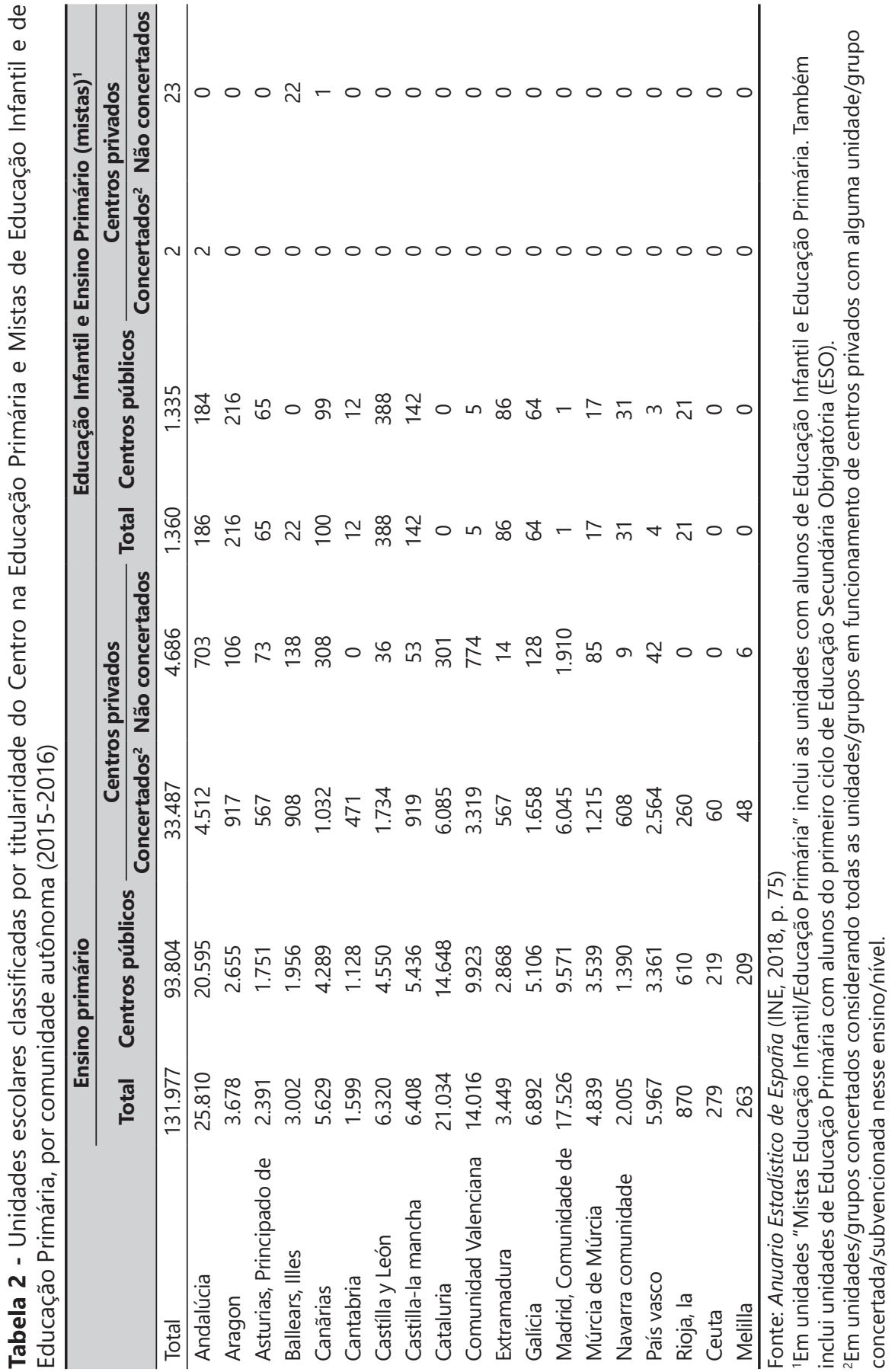


Com relação ao quantitativo de Centros Públicos para a Educação Primária, os dados demonstram um maior quantitativo de Centros Públicos, como também de Centros Mistos. Há de se considerar que o sistema público representa mais de dois terços do total de oferta do Ensino não universitário no país. Ao comparar o quantitativo de Centros Concertados, Centros Públicos e Centros Privados, permanece um quantitativo majoritário de instituições públicas - as financiadas pelo setor público - enquanto que os Centros Privados, mediante estudo de Torrubia e Embún (2009), mantêm uma presença residual, sendo inferior a 10\%.

Observam-se três regiões onde se verifica maior predomínio dos Centros Concertados, na média, são elas, o País de Vasco, Navarra e Catalunha. Por outro lado, as regiões da Melilla, Castilla-La Mancha, Canarias, Andalucia e Extremadura apresentam uma porcentagem superior a $75 \%$ do total de oferta educativa em Centros Públicos. Pode-se afirmar que o sistema educativo na Espanha, no que se refere à Educação Infantil e à Educação Primária, tem uma rede pública majoritária, entretanto, com uma rede considerável de Centros Concertados com gestão privada, sustentados por fundos públicos, de maneira que muitos Centros são vinculados a instituições religiosas.

Existem aspectos ambivalentes que foram produzidos mediante os efeitos da liberdade de escolha ${ }^{10}$ dos Centros escolares. Com o passar do tempo, o sistema de concertação converteu-se em um instrumento jurídico destinado a ampliar a escolha do Centro escolar para todos, o que fez aumentar a destinação de recursos públicos para instituições privadas e religiosas sem fins lucrativos (VILLARROYA-PLANAS; ESCARDIBUL FERRÁ, 2008).

Quanto ao financiamento dos Centros Concertados com fundos públicos, no que tange à sua eficiência e sua equidade, diversos aspectos foram evidenciados, dentre eles, destaca-se que os efeitos da igualdade de oportunidades de escolha do Centro evidenciaram que os Centros de titularidade concertados, majoritariamente, são frequentados por alunos provenientes de famílias que podem custear taxas, cotas cobradas por atividades escolares extras e serviços complementares (VILLARROYAPLANAS, 2003). Enquanto que nos Centros de titularidade pública encontram-se, em sua maioria, os alunos provenientes de famílias do entorno socioeconômico menos favorecido, como os imigrantes (TORRUBIA; EMBÚN, 2009).

Outra questão importante para sopesar é que a dualidade do sistema educativo nos territórios tem uma de suas explicações na relação com a riqueza econômica

\footnotetext{
${ }^{10}$ Ressalta-se que o artigo 27.3 da Constituição Espanhola reconhece como direito que os pais podem escolher e decidir quanto à formação religiosa e moral dos seus filhos (ESPAÑA, 1978).
} 
das comunidades autônomas, medida por meio do produto interno bruto (PIB) per capita, sendo um elemento desencadeador da aparição do setor privado de ensino. Medir (2016) constata que a relação entre alunos matriculados no setor público e outras variáveis socioeducativas desaparecem, como por exemplo, ao analisar-se por população, por número de alunos ou por porcentagem de estrangeiros. Essas variáveis não mostram um padrão tão claro da relação com a porcentagem de escolarização no setor público como o PIB per capita, como afirma o autor:

[...] la dualidade público/privado es especialmente marcada em aquellos territórios con mayor renta per cápita, puesto que acumulan porcentajes menores de alunos escolarizados en sistemas públicos. Razonando a la inversa, el sector privado se concentra em aquellos territórios más acaudalados (MEDIR, 2016, p. 504).

Ainda com relação à manutenção do ensino nos Centros Concertados, informes apresentados pela Comissão Europeia, na rede Eurydice ${ }^{11}$ (2019), explicitam que os recursos financeiros são destinados para programas estratégicos no sistema educativo espanhol, com algumas prioridades para a Educação Infantil e Primária, de maneira que os recursos são redistribuidos conforme a proporção aluno/professor (EURYDICE, 2019).

Os fundos públicos são majoritariamente provenientes do Ministério da Educação e Formação Profissional (MEFP) e das administrações educativas autônomas. Também contribuem outros ministérios e outras administrações, nomeadamente, autônomas e locais, todavia, em menor medida. Em linhas gerais, para a manutenção do financiamento e da gestão da Educação, as ações transcorrem com a função exercida pelo Estado, que estabelece anualmente o orçamento geral e as quantidades destinadas para a Educação, assim como a sua distribuição entre as diferentes etapas educativas e seus programas. No âmbito da sua competência, o Estado administra os fundos públicos para as cidades autônomas de Ceuta e de Melilla e os Centros do exterior (EURYDICE, 2019).

As comunidades autônomas administram os fundos públicos em seu território e decidem as quantidades destinadas para a Educação e sua distribuição entre as diferentes etapas do Ensino, programas e serviços, o que é detalhando anualmente em seus orçamentos. Esses fundos, mediante informes da Eurydice (2019), são provenientes de: a) Arrecadação de impostos e outros

\footnotetext{
${ }^{11}$ Tem por missão explicar como se organizam e funcionam os sistemas educativos na União Europeia por meio de publicações, estudos comparativos, indicadores e estatísticas (EUROPEAN COMMISION, 2020).
} 
rendimentos das comunidades autônomas; b) Transferências do Estado: as quantidades atribuídas para cada comunidade autônoma são determinadas por distintos parâmetros, especialmente o populacional. As administrações locais possuem fundos provenientes da arrecadação de impostos e outros rendimentos, e das transferências do Estado e da comunidade autônoma correspondente (EURYDICE, 2019).

As quantias dos fundos públicos são destinadas para efetiva manutenção da gratuidade para o ensino nos Centros Concertados privados, sendo estabelecidas nos orçamentos das administrações educativas correspondentes (EURYDICE, 2019). O Estado fixa, anualmente, em seu Orçamento Geral, o valor mínimo para o financiamento por unidade escolar e por quantidade de alunos atendidos simultaneamente por um professor. Mediante orçamento geral do país (ESPAÑA, 2018b), o valor do repasse do fundo público, apresentado no Quadro 1, inclui os três modelos econômicos de distribuição dos fundos para a provisão dos Centros Concertados, que são: salários dos professores, gastos variáveis e outros gastos.

Quadro 1 - Valor mínimo de financiamento público por unidade escolar para Centros Privados Concertados (valor em Euros) - 2018

\begin{tabular}{|c|c|c|}
\hline & $\begin{array}{l}\text { Comunidades } \\
\text { autônomas }\end{array}$ & Ceuta e Melilla \\
\hline Educação infantil primária & $38.437,17$ & $45.611,60$ \\
\hline Educação especial: educação básica e primária & $38.841,98$ & - \\
\hline $\begin{array}{l}\text { Educação especial: programas de formação } \\
\text { para a transição da vida adulta }\end{array}$ & $71.290,30$ & - \\
\hline ESO (primeiro e segundo curso) ${ }^{1}$ & $55.745,98$ & $67.788,05$ \\
\hline ESO (terceiro e quarto curso) & $62.945,21$ & $74.259,79$ \\
\hline Bachillerato & $75.003,13$ & - \\
\hline FP básico ${ }^{2}$ & $69.996,41-79.644,06$ & $69.482,13$ \\
\hline Ciclos formativos de grau médio ${ }^{3}$ & $67.329,71-75.492,56$ & - \\
\hline
\end{tabular}

Fonte: Presupuestos Generales del Estado de 2018 (ESPANA, 2018c).

${ }^{1} A$ quantidade evidenciada corresponde às unidades escolares cujos professores são licenciados. No caso de serem professores, o valor mínimo correspondente à unidade escolar seria de 46.640,36 euros ou 58.045,61 no caso das cidades de Ceuta e Melilla.

${ }^{2}$ Este montante varia de acordo com o grupo ao qual o Fundo Público (FP) básico pertence, uma vez que os Orçamentos Gerais do Estado dividem o FP básico em grupos, dependendo do nível de despesa envolvido.

${ }^{3}$ Este montante varia de acordo com o grupo ao qual pertence o ciclo formativo em questão, uma vez que os Orçamentos Gerais do Estado dividem os ciclos formativos de acordo com o número de horas e o nível de despesa que envolve. Além disso, o intervalo refletido na tabela refere-se ao financiamento do $1^{\circ}$ curso dos ciclos formativos (tradução nossa) 
O financiamento estatal dos programas co-financiados distribui-se entre as comunidades autônomas, segundo o acordado pela Conferência Setorial de Educação ${ }^{12}$. Para os critérios de distribuição, consideram-se o número de Centros Públicos por Ensino relevante para os programas e o número de alunos matriculados. O financiamento para a Educação na Espanha é proveniente dos impostos, taxas, preços públicos e outras receitas e também dos Fundos da União Europeia (EURYDICE, 2014).

Não foram alvo dessa investigação a análise sobre o valor do gasto por aluno e a relação por CCAA, no entanto, um dos aspectos da reprodução da dualidade escolar está no padrão do gasto relacionado com as transferências por subvenções, pois o gasto educativo médio por aluno não difere, em grande medida, por CCAA, sem que haja diferenças notáveis na gestão dos orçamentos públicos (MEDIR, 2016). Nas CCAA com maior presença do setor privado, a quantidade de gasto público com Educação veicula-se muito mais por meio das transferências para as escolas concertadas, o que desfavorece a gestão financeira do orçamento educativo do setor público, do que se transfere das mãos públicas para as mãos privadas. $\mathrm{Na}$ etapa não obrigatória, de 0 a 3 anos, e na etapa do ESO, há impacto muito maior para o setor privado. Todavia, a Educação das etapas de 3 aos 12 anos está, majoritariamente, sob predomínio do setor público.

Outro aspecto a evidenciar diz respeito às avaliações externas do PISA (Programa Internacional de Avaliação de Estudantes). Salienta-se que os resultados brutos nas provas dos alunos provenientes das escolas concertadas são mais elevados do que o dos alunos das escolas públicas. O motivo disso está relacionado com o fato de os Centros Concertados selecionarem seus alunos, ou seja, não se trata de um resultado oriundo da eficiência do modelo de gestão do próprio Centro. Todavia, essa questão indica que, se descontarem os efeitos associados à composição social dos alunos das escolas, as diferenças de rendimento acadêmico se tornarão estatisticamente não significativas. O que leva a supor que, ao avaliar o desenvolvimento do alunado, devem-se levar em consideração as diferenças, a qualidade do ensino e o tipo de aluno pertencente à escola (TORRUBIA; EMBÚN, 2009). Portanto, uma maior autonomia não, necessariamente, conduz a uma maior eficiência na gestão escolar.

No que se refere à distribuição do Gasto Público nas diferentes atividades e etapas educativas, a Educação Infantil e a Educação Primária, com a inclusão da Educação Especial, representaram 34,3\% do total do gasto público com Educação, no ano de

\footnotetext{
12 É um órgão representativo e deliberativo, de coordenação da política educativa em todo âmbito do Estado. Desde a sua constituição, em 1986, permite a cooperação das administrações educativas.
} 
2017. As demais etapas, isto é, a Educação Secundária e a Formação Profissional corresponderam a 29,6\% do gasto público com Educação, ao passo que o gasto com a Educação Universitária correspondeu a 19,9\%, além das bolsas e ajuda de custo, cujo gasto alcançou o percentual de 4,4\%, como se pode visualizar no Gráfico 1 .

Gráfico 1 - Distribuição do gasto público em Educação por atividade (2017)

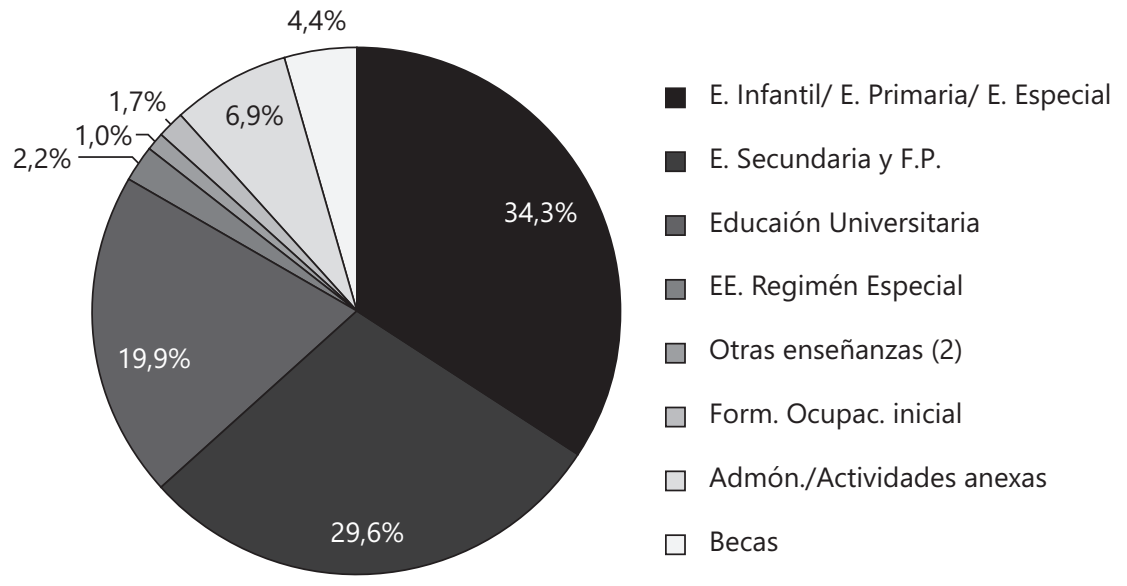

Fonte: MEFP. Estadística del Gasto Público en Educación (ESPAÑA, 2017, p. 04).

Um dos objetivos dos Fundos da União Europeia é reforçar a coesão econômica e social, ajudar a combater o desemprego e impulsionar a competitividade econômica mediante o apoio e a inovação da formação e da Educação. As prioridades da Espanha, estabelecidas no Acordo da Associação com a Comissão Europeia, entre outras prioridades, incluem: $\mathrm{O}$ aumento da participação no mercado de trabalho e na produtividade laboral, assim como melhorar a Educação e a capacitação para o trabalho; b) Políticas de inclusão, com especial atenção aos jovens e aos grupos mais vulneráveis (ESPAÑA, 2016).

Os recursos canalizam-se mediante Fundos Estruturais, especialmente, o Fundo Social Europeu (FSE). O FSE financia iniciativas para melhorar os sistemas educativos e formativos, apoia medidas para lutar contra o abandono e a evasão, na área da Educação, e para a formação profissional adequada dos jovens, a fim de suas oportunidades no mercado laboral (EURYDICE, 2014).

Quanto à avaliação da experiência educativa desenvolvida pelos Centros Concertados, desde 1985, há de se evidenciar também a presença da segregação entre o sistema 
público e o sistema concertado na Espanha. Conforme pondera Calero (2006), nos Centros Concertados, concentra-se um alunado mais seleto acadêmica e socialmente mais favorecido, com proporção bem menor de imigrantes, se comparado com os Centros Públicos. Nesse sentido, o sistema de concertos tem favorecido a fuga da classe média do setor educativo público, de forma que, desde o final da década de 1990, essa classe tem optado pelo sistema concertado de ensino.

\section{Considerações finais: algumas conjecturas e inquietações}

Diante do exposto, destacam-se algumas considerações para pensar o futuro das políticas, da gestão e do financiamento dos Centros Concertados de Educação Infantil e Educação Primária na Espanha. Salientam-se que as políticas instituídas para o repasse do financiamento público aos Centros Concertados, que estão vigentes na Espanha desde 1985, concretizaram-se em um período da história de ascensão da globalização, no qual as políticas de descentralização oriundas da reestruturação da produção, do pós-fordismo das empresas, materializaram-se também na gestão e no financiamento educacional do país.

Conforme mencionado na seção 2 , o estabelecimento de escolas concertadas e o seu financiamento foram desenhados e consolidados no contexto em que se firmavam a Constituição Espanhola de 1978, a Lei Orgânica do Direito à Educação (LODE) no 8 de 1985 (ESPAÑA, 1985) e, depois, a Lei Orgânica LOE nº 2 de 2006 (ESPAÑA, 2006); assim, a descentralização educativa ocorreu paralelamente ao processo de democratização do Estado, de forma que a descentralização da Educação parte da democratização do país. Nesse sentido, as competências do sistema educacional foram delegadas em virtude do manto constitucional, estatutário, político e institucional, portanto, fruto de uma organização territorial própria e marca simbólica da política constitucional.

Os efeitos da política de descentralização trouxeram conquistas, essencialmente, democráticas, mas também abriram espaços para a atuação do setor privado em parceria com o setor público, portanto, visualizou-se um maior quantitativo de Centros Concertados no País de Vasco, Navarra e Catalunha. Todavia, em Melilla, Castilla-La Mancha, Canarias, Andalucia e Extremadura verificou-se uma porcentagem superior a $75 \%$ do total de oferta educativa em Centros Públicos. No que se refere à Educação Infantil e à Educação Primária, a Espanha tem uma rede pública majoritária, contudo, tem sido ampliada uma rede considerável de Centros Concertados com gestão privada, sustentada por fundos públicos e, em sua maioria, são confessionais. 
Cabe salientar que, no panorama educativo espanhol, há realidades distintas em suas CCAA, com diferenciações em seus sistemas de ensino, o que também desencadeiam formulações de políticas educativas locais ambivalentes. Dentre esses aspectos, destaca-se, como resultado da política de destinação de recursos públicos aos Centros Concertados, certa dualidade entre os setores público e privado, marcada por territórios com maior renda per capita, e que acumulam um quantitativo menor de alunos escolarizados em sistemas públicos, o que revela que os sistemas privados de ensino concentram-se, majoritariamente, em territórios mais ricos e, ainda, que os resultados das avaliações externas podem não representar uma eficiência de gestão, como apresentado na seção 3.

Com relação ao papel dos Conselhos Escolares, ressalta-se como aspecto positivo a participação democrática e coletiva na construção, monitoramento e autonomia, no que tange às políticas educacionais no país. A participação coletiva e institucionalizada na Espanha é um fenômeno oriundo das reinvindicações provenientes da concepção progressista de Educação.

Ficam notórios três aspectos que, essencialmente, estão presentes no resultado da configuração política apresentada, são eles: 1) As políticas de descentralização e seus efeitos na redução do gasto público com a Educação; 2) Dualidades entre os setores público e privado a partir da renda per capita; 3) Equidade e aspectos segregadores para o sistema de ensino espanhol, a partir das diferenças entre escolas concertadas e públicas. Há necessidade de políticas, gestão e financiamento da Educação, de maneira que a relação entre o setor público e o setor privado não resulte em conflitos, no que se refere à igualdade de condições e de acesso, participação coletiva e democrática na Espanha. Ressalta-se a necessidade de manutenção da participação coletiva, para a construção de políticas educacionais mais equitativas e não segregatórias na Espanha. Que os Centros Públicos e Concertados sejam entendidos como sinônimos de qualidade escolar para todos, sem distinção. 


\section{Políticas educativas y financiación de los centros concertados en España}

\section{Resumen}

El artículo es resultado de una búsqueda exploratoria y documental que tuvo como enfoque las politicas educacionales, la administración y el financiamiento a los Centros de Educación Infantil y Primaria Concertados en España, en la cual se investigó los aspectos historiales y políticos cuanto a la estructura y organización de la política educativa a partir del proceso de descentralización en el pais. Se priorizó el análisis del papel del Consejo Escolar a la formación de la política educacional y española y los aspectos relacionados a la manutención de las enseñanzas en los Centros de Educación Infantil y Primaria Concertados, a fin de aprender los presupuestos en el periodo de 2016-2017. Se presenta los aportes y las implicaciones a los Centros Concertados en la cual el resultado evidencia la necesidad de la manutención de la participación colectiva a la construcción de políticas educacionales más equitativas y no segregantes en España.

Palabras clave: Políticas Educativas. Financiamiento de la Educación. Centros Concertados. Educación Infantil. Educación Primaria. España.

\section{Educational policies and the financing of concerted centers in Spain}

\section{Abstract}

The abstract is a result of a exploratory and desk research that has a subject the educational policies, the management and the financing for the Childhood and Primary Education Concerted Centers, which was investigated the historical and political aspects as structure and the political organizational starting by the process of decentralization in the country. It was prioritized the analysis of the role of the School Board for the formulation of the Spanish educational politic and the aspects related to the maintenance of the Childhood and Primary Education Concerted Centers, with the need of learning the assumption budget in the period of 2016-2017. It was presented about the investments and the implication of the collective participation for the construction of educational politics more fair and non-segregate in Spain.

Keywords: Educational Policies. Education Financing. Concerted Centers. Child Education. Primary Education. Spain. 


\section{Referências}

CALERO, J. Los déficits de la educación española. Temas para el Debate, [s. 1.], n. 140, p. 47-49, jul. 2006.

CARNOY, M. Globalización y reestructuración de la educación. Revista de Educación, Madrid, n. 318, p. 145-162,1999.

ESPAÑA. Constitución española: Aprobada por Las Cortes en sesiones plenarias del Congreso de los Diputados y del Senado celebradas el 31 de octubre de 1978. Madrid: Agencia Estatal Boletín Oficial del Estado, 1978. Disponível em: https://www.boe.es/legislacion/documentos/ ConstitucionCASTELLANO.pdf. Acesso em: 20 jan. 2020.

ESPAÑA. Ley de 13 de agosto de 1940 por la que se crea el Consejo Nacional de Educación. Boletin Oficial del Estado, Madrid, 4 sep. 1940. Disponível em: https://www.boe.es/datos/pdfs/BOE//1940/248/A06172-06175.pdf. Acesso em: 7 set. 2020.

ESPAÑA. Ley 14/1970, de 4 de agosto, General de Educación y Financiamiento de la Reforma Educativa. Boletín Oficial del Estado, Madrid, 6 ago. 1970. Disponível em: https://www.boe.es/diario_boe/txt. php?id=BOE-A-1970-852. Acesso em: 18 jan. 2020.

ESPAÑA. Ley $n^{\circ}$ 6, de 3 de julio de 2018, de Presupuestos Generales del Estado para el año 2018. Boletín Oficial del Estado, Madrid, 4 jul. 2018

ESPAÑA. Ley Orgánica n ${ }^{\circ}$ 5, de 19 de junio de 1980, por la que se regula el Estatuto de Centros Escolares [LOECE]. Boletín Oficial del Estado, Madrid, 27 jun. 1980.

ESPAÑA. Ley Orgánica n. ${ }^{\circ}$ 1, de 3 de octubre de 1990, de Ordenación General del Sistema Educativo [LOGSE]. Boletín Oficial del Estado, Madrid, 4 oct. 1990.

ESPAÑA. Ley Orgánica nº 2, de 3 de mayo de 2006, de Educación [LOE]. Boletín Oficial del Estado, Madrid, 4 mai. 2006.

ESPAÑA. Ley Orgánica no 8, de 3 de julio de 1985, Reguladora del Derecho a la Educación [LODE]. Boletín Oficial del Estado, Madrid, España, jul. 1985.

ESPAÑA. Ley Orgánica n. ${ }^{\circ} 8$ de 9 de diciembre de 2013, para la mejora de la calidad educativa [LOMCE]. Boletín Oficial del Estado, Madrid, 10 dic. 2013. 
ESPAÑA. Lei Orgânica n. ${ }^{\circ}$ 10, de 23 de diciembre de 2002, de Calidad de la Educación. [LOCE]. Boletín Oficial del Estado, Madrid, 24 dic. 2002.

ESPAÑA. Real Decreto n. ${ }^{\circ} 694$ de 2007, de 1 de junio, por el que se regula el Consejo Escolar del Estado. Boletín Oficial del Estado, Madrid, 13 jun. 2007

ESPAÑA. Ministerio de Educación y Formación Profesional. Estructura del sistema educativo español. Madrid, 2018a. Disponível em: http://www.educacionyfp.gob.es/educacion-mecd/in/sistema-educativo/ portada.html. Acesso em: 10 jan. 2020.

ESPAÑA. Ministério de Educacion y Formacion Profesional. Estadística del gasto público en educación: resultados provisionales. Madrid, 2017.

ESPAÑA. Ministério de Educacion y Formacion Profesional. Consejo Escolar del Estado. Informe 2018 sobre el estado del sistema educativo: curso 2016-2017. Madrid, 2018b. Era Ministério

ESPAÑA. Ministério de Educacion y Formacion Profesional. Consejo Escolar del Estado. Madrid, 2020. Disponível em: http://www.educacionyfp.gob.es/en/ mc/cee/portada.html. Acesso em: 7 set. 2020.

ESPAÑA. Ministério de Educacion y Formacion Profesional. Instituto Nacional de Evaluación Educativa. Panorama de la educación: indicadores de la OCDE 2016. Madrid, 2016.

ESPAÑA. Ministerio de Hacienda. Secretaría de Estado de Presupuestos y Gasot. Presupuestos generales del Estado 2018. Madrid, 2018c. Disponível em: https://www.sepg.pap.hacienda.gob.es/sitios/sepg/es-ES/Presupuestos/ PGE/PresupuestosEjerciciosAnteriores/Paginas/Ejercicio2018.aspx. Acesso em: 26 jan. 2021.

EUROPEAN COMMISION. EACEA National Policies Platform. [S. 1.], 2020. Disponível em: https://eacea.ec.europa.eu/national-policies/. Acesso em: 7 set. 2020.

EURYDICE. Comissão Europeia/EACEA. O financiamento das escolas na Europa: mecanismos, métodos e critérios de financiamento público: Relatório Eurydice. Lisboa: Direção-Geral de Estatísticas da Educação e Ciência; 2014.

EURYDICE. Estructura del Sistema educativo español. Bruxelas, 2019. 
EVANGELISTA, O.; SHIROMA, A. O. Subsídios teórico-metodológicos para o trabalho com documentos de política educacional: contribuições do marxismo. In: CÊA, G.; RUMMERT, S. M.; GONÇALVES, L. Trabalho e educação: interlocuções marxistas. Rio Grande: Editora da FURG, 2019. p. 84-120.

FUNDACIÓN EUROPEA SOCIEDAD Y EDUCACIÓN. Indicadores comentados sobre el estado del sistema educativo español. Bruxelas, 2018.

HERNÁNDEZ-DÍAZ, J. M. Presentación: nota sobre modernización educativa en la historia de Iberoamérica. Revista História da Educação, Salamanca, n. 36. p. 27-29, 2017. http://dx.doi.org/10.14201/hedu2017362729

INSTITUTO NACIONAL DE ESTADÍSTICA - INE. Anuario Estadístico de España. 2018. Madrid, 2018. Disponível em: https://www.ine.es/prodyser/ pubweb/anuarios_mnu.htm. Acesso em: 20 abr. 2020.

MEDIR, L. La politica educativa em España: uma estrutura de oportunidades aberta y multinivel. La Rjoja: Fundación DIALNET, 2016. Disponível em: https://dialnet. unirioja.es/servlet/articulo?codigo=6133213. Acesso em: 20 jan. 2020.

MOREIRA, J. A. S. Políticas de financiamento e gestão da educação básica (1990-2010): os casos Brasil e Portugal. Maringá: EDUEM, 2015.

PUELLES-BENITEZ, M. Educación y autonomía en el modelo español de descentralización. Revista de Educación, [s. 1.], n. 309, p. 163-193, 1996.

PUELLES-BENITEZ, M. El Consejo Escolar del Estado: antecendentes, evolución y situación actual. Participación Educativa, Madrid, n. 0, p. 44-49, nov. 2005.

SOUZA, A. R. A política educacional e seus objetos de estudo. Revista de Estúdios Teóricos y Epistemológicos en Política Educativa, [s. 1.], v. 1, n. 1, p. 75-89, ene./jum. 2015.

SOUZA, D. B.; BATISTA, N. C. Educação comparada Brasil-Espanha: estado da arte 1990-2014. Ensaio: Avaliação e Políticas Públicas em Educação, Rio de Janeiro, v. 26, n. 100, p. 723-758, jul./set. 2018. https://doi.org/10.1590/s0104-40362018002601046

SOUZA, D. B. Planejamento e planos de educação na Espanha: evolução da produção acadêmica e científica 1978-2016. Ensaio: Avaliação e Políticas Públicas em Educação, Rio de Janeiro, v. 29, n. 110, p. 70-89, jan./mar. 2021. https://doi.org/10.1590/s0104-40362020002802519 
TORRUBIA, M, J. M.; EMBÚN, D. P. X. Los efectos de los conciertos sobre la eficiencia y la equidad del sistema educativo español. Madrid: Laboratorio de Alternativas, 2009. (Documento de trabajo, n. 154).

VILLARROYA-PLANAS, A. La financiación de la enseñanza privada no universitaria en España. Revista de Educación, [s. 1.], n. 330, p. 187-204, 2003. Disponível em: https://dialnet.unirioja.es/servlet/articulo?codigo=624805. Acesso em: 20 jan. 2020.

VILLARROYA-PLANAS, A.; ESCARDIBUL FERRÁ, J. O. Políticas públicas y posibilidades efectivas de elección de centro en la enseñanza no universitaria en España. Profesorado: Revista de Curriculum y Formación del Profesorado, v. 12, n. 2, p. 90-115, 2008. Disponível em: https://dialnet.unirioja.es/servlet/articulo? codigo $=2741586$. Acesso em: 20 abr. 2020.

\section{Informações sobre os autores}

Jani Alves da Silva Moreira: Doutora em Educação pela Universidade Estadual de Maringá. Docente Adjunta do Departamento de Teoria e Prática da Educação e do Programa de Pós-Graduação em Educação da mesma universidade. Contato: jasmoreira@uem.br

iD http://orcid.org/0000-0002-3008-0887

Ângelo Ricardo de Souza: Doutor em Educação: História, Política, Sociedade pela Universidade Pontifica Católica de São Paulo. Professor Associado da Universidade Federal do Paraná, onde atua no Núcleo de Políticas Educacionais e no Programa de Pós-Graduação em Educação. Bolsista de Produtividade em Pesquisa do CNPq - Nível 1D. Coordenador Adjunto da Área de Educação na Capes. Contato: angelo@ufpr.br (iD) https://orcid.org/0000-0002-0246-3207

José María Hernández Díaz: Doctor em Educación por la Universidad de Salamanca (Usal). Catedrático de Teoría e História de la Educación. Coordinador del Programa de Doctorado en Educación por la Universidad de Salamanca. Contato: jmhd@usal.es (iD) https://orcid.org/0000-0001-7604-1544 